\title{
FUNCTIONALITY ASSESSMENT OF ECODESIGN SUPPORT SYSTEM
}

\author{
Ewa Dostatni, Jacek Diakun, Damian Grajewski, \\ Radosław Wichniarek, Anna Karwasz \\ Poznań University of Technology, Faculty of Mechanical Engineering and Management, Poland \\ Corresponding author: \\ Ewa Dostatni \\ Poznań University of Technology \\ Faculty of Mechanical Engineering and Management \\ Chair of Management and Production Engineering \\ Piotrowo 3, 60-965 Poznań, Poland \\ phone: +48616652731 \\ e-mail: ewa.dostatni@put.poznan.pl
}

Received: 23 January 2015

Accepted: 8 February 2015

\begin{abstract}
In the paper the issue of ecological-oriented product design is addressed. The definitions that concern product design are listed and the factors that make them important for the manufacturers are indicated. The method of ecological-oriented product assessment during the design process (implemented in the 3D CAD system), drawn-up by authors, is used for the analysis. The assessment of real household appliance using the method is presented and the conclusions from the evaluation are drawn.
\end{abstract}

KEYWORDS

eco-design, product modeling, CAD, PLM, agent technology.

\section{Introduction}

Ecodesign assumes that the environmental impact of a product should be considered already at the product design stage. The literature offers a number of definitions of the term:

- Ecodesign is a new approach to product design and consists in the identification of the environmental impact associated with the product and considering it in the design process at an early stage of product development [1],

- Ecodesign is also referred to as design for environment, environmental design, ecological design, sustanaible product design, and green design. It introduces an additional dimension to the traditional design: the design is evaluated for the environmental impact of the product throughout its life cycle [2],

- Ecodesign means the integration of environmental aspects into product design with the aim of improving the environmental performance of the EuP throughout its whole life cycle [3],
- Ecodesign - one of the systemic tools in environment management, which assumes that the product and services introduced on the market should have minimal environmental impact throughout their life cycle [4].

Given the growing importance of eco-design and strict regulations of the European Union, it is increasingly often implemented in manufacturing companies.

\section{The importance of the introduction of environmental design to manufacturing companies}

There are various reasons motivating companies to implement environmental design. The main determinants have been divided into internal and external factors. The internal factors include:

- product quality - the level of environmental quality of the product translates into an overall improvement in the product quality, its functionality, reliability and serviceability, 
- cost reduction - reducing the consumption of energy and materials, possibility to re-use device components,

- stimulation of technological innovation - the search for new technologies and environmentally oriented solutions,

- sense of responsibility - a sense of awareness of the company's development among decision makers and the staff,

- improvement of company and product image higher product rating (and thus company rating) by consumers,

- increase of employee motivation - reduction of the environmental impact of the process and product contributes to the overall improvement in the safety and health of workers.

External factors determining the introduction of environmental design:

- the cost of waste - waste treatment generates such costs that prevention, i.e. designing products with a view of reducing the volume of waste to a minimum, becomes more cost-effective,

- government policy - legal regulations related to ecology, EU directives and regulations (including regulations for countries from outside the EU but operating on its territory),

- market demand and competition - the requirements of customers, suppliers, and distributors have become a strong incentive for the environmental improvement of products,

- commercial and industrial organizations - promote participation in environmental activities (and sometimes force their members to such participation),

- environmental criteria of awarding prizes for projects - in prestigious product contests the environmental condition is one of the main criterion that has to be met [5].

Most often companies are driven to implement ecodesign by a combination of both external and internal factors.

Research shows that companies do not follow ecodesign systematically $[6,7]$. The main cause behind this situation is the lack of systemic approach to the existing practice and lack of tools that support ecodesign [7-10], and no interest in including product development based on eco-innovation into the business strategy $[8,9,11,12]$. The companies' less than proactive approach to ecodesign in also caused by the lack of an action plan in the continuous improvement of ecodesign $[8,13]$, as well as the difficulties in defining and prioritizing the factors which affect the environmental performance of products and introducing them to pilot projects [13].

\section{The essence and principles of ecodesign}

The core of sustainable design lies in the prevention or reduction of the negative environmental impact of all activities related to the production of a new product throughout its life cycle. The earlier the environmental aspects are considered in the design process, the more effective it is. The ecodesign of a product's life cycle requires the following principles to be observed [14]:

- saving natural resources, using renewable and easily accessible materials,

- extension of product life,

- design with re-use in mind,

- design considering recycled materials,

- design for easy disassembly,

- minimum use of harmful substances (or their elimination, if possible),

- environmentally friendly production,

- possibly minimized environmental impact during product lifetime,

- use of environmentally friendly packaging,

- reduction or (if possible) complete elimination of materials that cannot be recycled.

When new products are designed, certain principles must be observed for the designed product to be environmentally friendly. A designer should be familiar with compatible materials and should have access to them. Incompatible materials affect the quality of the recycled material. Only materials which together form a compatible combination should be used in production. Based on compatibility tables (matrices) a designer defines which materials may be combined to make recycling as simple as possible. Various matrices are used for metal alloys, e.g. aluminum and steel, and for plastics, e.g. thermoplastics. There are also matrices for recycling complete products. It is also crucial to minimize material diversity to reduce the probability of material incompatibility issues. It is also important to consider the manner and type of joints to be used in the product. The joints should be designed to ensure quick and smooth disassembly, particularly when the use of incompatible or hazardous materials is unavoidable due to functional reasons $[15,16]$.

\section{Computer-aided ecodesign}

Today sustainable products are designed with the use of specially designed computer systems. Companies which intend to implement the ecological design can also use a broad array of support tools. These include ecodesign methods and IT systems [6], 
the most important of which include: "Design for Environment (DfE) Matrix" [17], "Ecodesign PILOT" [18], "Environmental Effect Analysis" [19, 20], "Environmental Quality Function Deployment" (EQFD), "Environmental Design Industrial Template" (EDIT) [21], "Life Cycle Assessment" (LCA) [22, 23], "Ten Golden Rules" [24], "Alternative Function Fulfillment" [25], "Strategy wheel" [26], and other. Additional modules for computer aided design (CAD) comprise another group of tools. One exam-

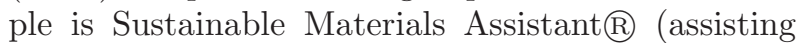
in the selection of environmentally friendly materials) by Autodesk Labs, to be used with Autodesk Inventor ${ }^{\circledR} 2009$ software. It is a tool which assists decision-making in the selection of environmentally friendly materials, in order to reduce the negative environmental impact of products while ensuring appropriate operational parameters [27]. The application SolidWorks Sustainability, another example, is a part of the SolidWorks package, which includes design, simulation, sustainable development, technical communication, and data management. It is a practical tool for implementing sustainable development strategies during product design. The application includes process models and life cycle assessment databases used in the GaBi software. SolidWorks Sustainability takes into account four key environmental indicators: carbon footprint, total energy consumption, and impact on air and water quality [28].

The examples above demonstrate that CAD software developers have already noted the need to consider environmental aspects at an early stage of product design. However, the applications are modules closely tied to specific CAD software. The method which supports environmental design, presented below, is recycling-oriented. It belongs to the group of tools discussed above, but it allows designers to assess product recyclability whichever CAD system is used.

\section{Recycling-oriented method to support ecodesign}

Our method, which facilitates product recyclability evaluation at design stage, is based on the recycling product model (RpM) and agent technology. The RpM, developed during the geometric modelling phase, includes the data necessary for a comprehensive product recyclability evaluation already at the design stage, allowing the designer e.g. to select appropriate solutions that facilitate future disassembly and to choose materials most suitable in terms of future recycling. The RpM has been implement- ed to the CAD 3D system and served as a basis to design an IT tool (an application) which facilitates the design process taking into account the recycling aspects. The application includes also a knowledge base, which accumulates the information on already completed projects. It is used by the system to offer suggestions when new products are designed, taking into account the aspects related to recycling. The software of the application uses the agent technology [29]. Agents follow the work of the designer in the $3 \mathrm{D}$ CAD system, monitor the changes made in the design, assess their impact on the parameters relevant to recycling, and provide suggestions of product improvements to facilitate its recycling. The use of the agent technology and RpM in the application enabled automatic support for the recycling aspect of designing, without having to re-examine the product structure, manually aggregate the parameters relevant for the adopted method of product recyclability evaluation, and to re-introduce them to third party systems. The following is a description of the practical application of the system in recyclability assessment of a sample product modeled using a CAD 3D system.

\section{Recyclability evaluation during product design}

A sample CAD 3D model was developed to conduct a product recyclability evaluation. A household appliance made by AMICA Wronki S.A. was subject to recyclability evaluation. The model we developed included various combinations of joints and allowed us to assign extended material and disassembly attributes necessary for the recyclability evaluation. It was also possible (in its agent part) to conduct the calculation of recyclability evaluation measures for connected elements made of compatible and incompatible materials. Figure 1 presents a product model in the CAD system.

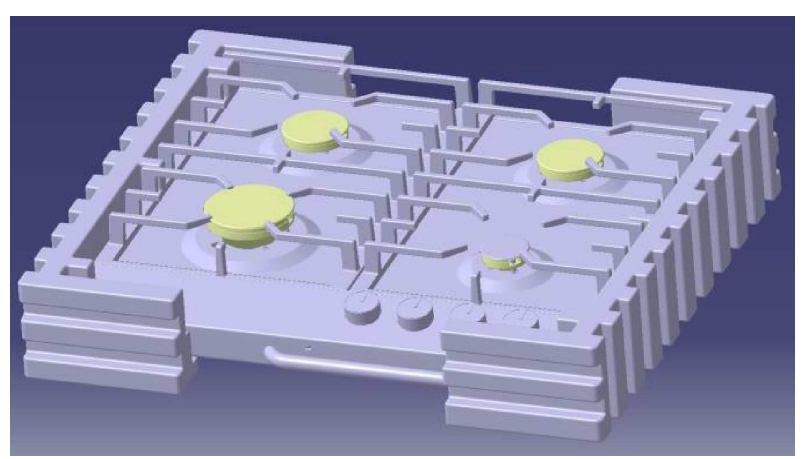

Fig. 1. Product model in CAD 3D. 
The CAD 3D model with the possible combinations of joint types was examined according to the following procedure:

- development of a 3D model of all product components,

- development of a recycling model (RpM),

- recyclability evaluation (calculations of recyclability evaluation measures by the agent system).

In the first step, we made geometric 3D models of the product elements (of the examined connection). Then, we defined the necessary geometric constraints to determine the relevant geometric relations between the parts. Based on the geometric model (assembly model), the recycling model was developed. Within the recycling model [16] the following were defined:

- the product category (type),

- extended material attributes,

- the model of connections between the product elements.

The recycling model is made in a $3 \mathrm{D}$ CAD environment through a graphical user interface built in the CATIA system. The assignment of the product to a specific type is made in the project's global settings window. In the product type selection field we indicated the type (category) of the model uploaded to the CATIA system. One of the following types may be selected "small household appliance", "large household appliance", and "other". The database with extended material attributes, defined earlier, was also uploaded. It included the basic groups of construction materials and plastics (Fig. 2).

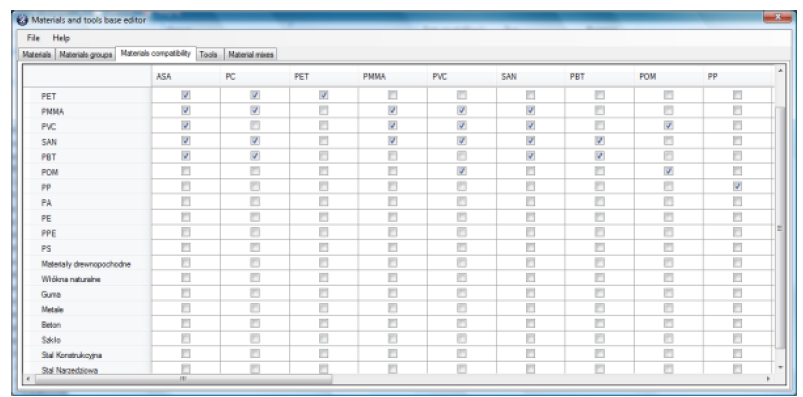

Fig. 2. Materials database.

For each material the basic attribues and properties were defined. The basic material groups were specified and the compatibility matrix was defined. The database also makes it possible to save the information on the set of tools needed for the disassembly process and the information on the existing material "mixtures" (elements which cannot be recycled).

Next, a model of joints between the product elements must be created (connection constraints). The task begins with determining to which group the given element of the product belongs (from the point of view of the role the element may play in the joints: connecting, combined, or connecting-combined element) (Fig. 3).

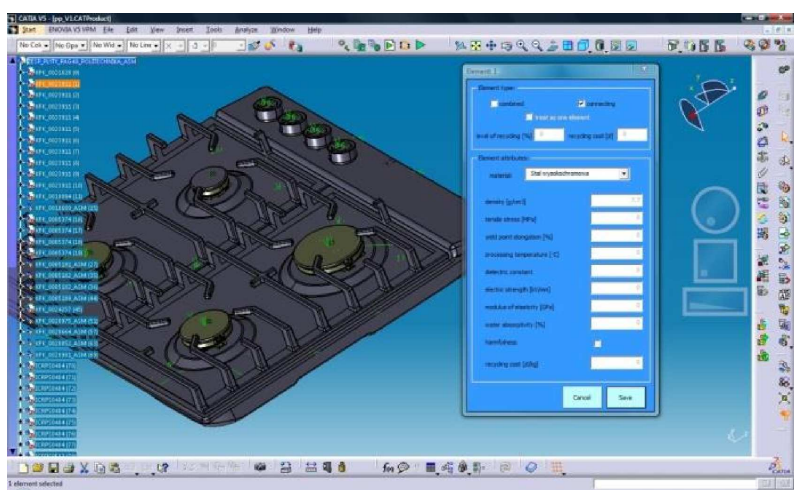

Fig. 3. Edition of properties of a connecting element from any assembly level.

Having defined the properties of all elements of the examined sample product (assembly), we specified the connection constraints between the elements of the designed product (Fig. 4). Each joint must consist of at least two combined elements, and the algorithm that verifies the correctness of data prevents the user from saving the information before this basic condition is met. The list of elements which make up any joint can be viewed and edited. The user can indicate an element in the design which meets the following criteria:

- its immediate parent element in the product structure is the element for which a joint is declared,

- it is one of the combined elements,

- it does not belong to the combined elements of the declared joint.

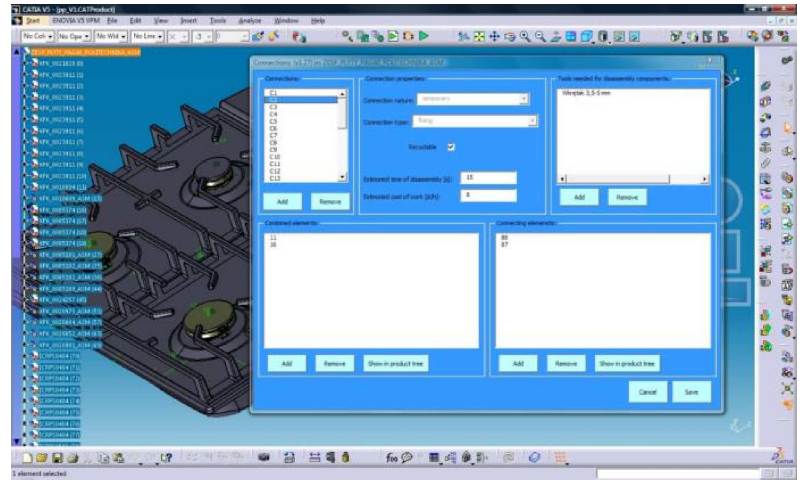

Fig. 4. Joints edition window (where connection constraints are made) in an assembly.

The minimum number of connecting elements required for a joint to be considered correct depends 
on the type of the joint. The information about the tool to be used during disassembly of the joint for recycling was also added to the declared joint.

Further analysis of the product takes place in the agent part. Using data exchange interface between $3 \mathrm{D}$ CAD system and the agent system, RpM data are transferred to the agent system. It is based on the universal data exchange format (Fig. 5).

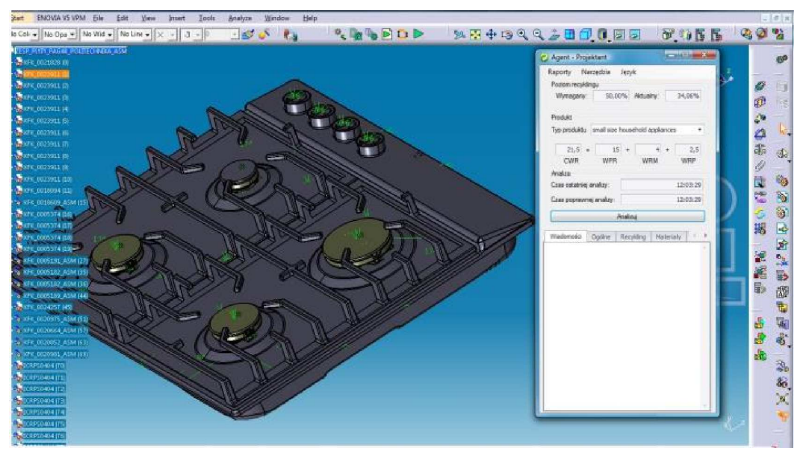

Fig. 5. On the left: Rough ACD 3D models, on the right: agent system interface - after the analysis.

The agent system provides information on the values of product recyclability evaluation measures, e.g. the level of recyclability of each element (basic or complex) comprising the designed product. The impact of each element or component on the ratio of entire product is also calculated (Fig. 6).

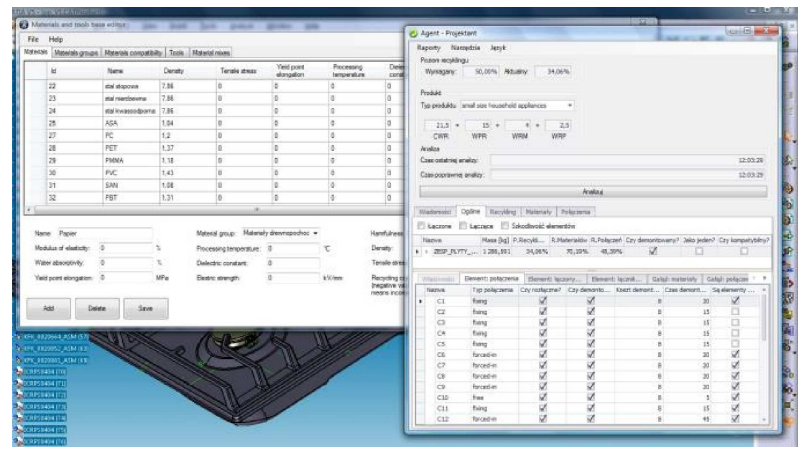

Fig. 6. Agent system interface at work - after the analysis.

During the analysis, if the agent system discoveres errors, e.g. inconsistency in the product structure, an appropriate message will be displayed on the user's screen.

\section{Conclusions}

The study allowed us to verify the functionality of the system using actual industrial data. The next step will be to examine several variants of the product model, with a change of the parameters which influence the results of recyclability evaluation (e.g. different types of joints or materials). This will allow us to compare and assess the influence of the parameter change on the results of the recyclability evaluation. The recycling product model which we developed may be implemented in the majority of popular CAD 3D systems, without having to modify the source code. However, adding that to the set of the basic functions of CAD 3D (e.g. as a separate module of the CAD $3 \mathrm{D}$ system) would certainly prove to be a better option. A complete integration would allow for automatic recall of model analysis by the agent system after a change in its geometry. In addition, it would be possible to introduce an automatic exchange of data with a PLM system that supports product development processes throughout the life cycle.

\section{References}

[1] Environmental management. Considering environmental aspects in the designer and product development, PKN-ISO/TR 14062.

[2] http://www.centrum.pemp.pl/dokumenty/eco/.

[3] Directive 2005/32/Ec of the European Parliament and of the Council of 6 July 2005.

[4] Janicka M., Hewelke P., Ecodesign as an important tool of environment protection as illustrated by electric and electronic equipment, Inter-faculty Environment Protection Studies at the Warsaw University of Life Sciences, p. 29.

[5] Frediel K., The process of implementing ecodesign in industry, research sources of Materials Recycling Center of Excellence (MRC), Wrocław University of Technology, http://www.ecodesignarc.info, access January 2015.

[6] Pigossoa D.C.A., Rozenfelda H., McAlooneb T.C., Ecodesign maturity model: a management framework to support ecodesign implementation into manufacturing companies, Journal of Cleaner Production, 15, 160-173, 2013.

[7] Boks C., The soft side of ecodesign, Journal of Cleaner Production, 14, 1346-1356, 2006.

[8] Brezet H., Rocha C., Towards a model for productoriented environmental management systems, Sustainable Solutions: Developing Products and Services for the Future, Charter M., Tischner U. [Eds.], Sheffield, Greenleaf Publishing, 2001.

[9] Baumann H., Boons F., Bragd A., Mapping the green product development field: engineering, policy and business perspectives, Journal of Cleaner Production, 10, 409-42, 2002. 
[10] Dewulf W., Duflou J.R., Integrating eco-design into business environments: a multi-level approach, Product Engineering: Eco-design, Technologies and Green Energy Sources, Talaba D., Roche T. [Eds.], Springer, p. 539, 2004.

[11] Pascual O., Stevels A., Ecodesign in industry is not an environmental issue, Proceedings of Electronic Goes Green, Berlin, pp. 855-859, 2004.

[12] Luttropp C., Lagerstedt J., EcoDesign and the ten golden rules: generic advice for merging environmental aspects into product development, Journal of Cleaner Production, 14, 1396-1408, 2006.

[13] Boks C., Stevels A., Essential perspectives for design for environment, experiences from the electronics industry, International Journal of Production Research, 45, 4021-4039, 2007.

[14] Adamczyk W., The ecology of products, Polish Economic Publishing House, Warsaw, 2004.

[15] Dostatni E., Karwasz A., Diakun J., Method for estimating recycling costs of household appliances at product design stage, Innovation in Management and Production Engineering, Knosala R. [Ed.], Publishing House of the Polish Association for Production Management, Opole, pp. 298-306, 2013.

[16] Dostatni E., Diakun J., Karwasz A., Grajewski D., Wichniarek R., Ecodesign of products in CAD $3 D$ environment with the use of agent technology, Publishing House of the Poznań University of Technology, Poznań, 2014.

[17] Yarwood J., Eagan P., Design for Environment a Competitive Edge for the Future, Minnesota Office of Environmental Assistance, 2003.

[18] Wimmer W., Pamminger R., Stachura M., Grab R., ECODESIGN in the electronics industry - achieving legal compliance with the EU-directives and environmentally improving products by using the new EEE-PILOT, 2005, Fourth International Symposium on Environmentally Conscious Design and Inverse Manufacturing Eco Design, pp. 671-677, 2005.
[19] Lindahl M., Engineering designers' experience of design for environment methods and tools - requirement definitions from an interview study, Journal of Cleaner Production, 14, 487-496, 2006.

[20] Tingström J., Karlsson R., The relationship between environmental analyses and the dialogue process in product development, Journal of Cleaner Production, 14, 1409-1419, 2006.

[21] Spicer A., Wang M.H., Environmental design industrial template (EDIT): a software tool for analysis of product retirement, Journal of Cleaner Production, 5, p193-19, 1997.

[22] Rydberg T., Cleaner products in the Nordic countries based on the life cycle assessment approach: the Swedish product ecology project and the Nordic project for sustainable, Journal of Cleaner Production, 3, 101-10, 1995.

[23] Finnveden G., Moberg Å., Environmental systems analysis tools-an overview, Journal of Cleaner Production, 13, 1165-1173, 2005.

[24] Luttropp C., Lagerstedt J., EcoDesign and the ten golden rules: generic advice for merging environmental aspects into product development, Journal of Cleaner Production, 14, 1396-1408, 2006.

[25] Van Der Zwan F., Bhamra T., Alternative function fulfilment: incorporating environmental considerations into increased design space, Journal of Cleaner Production, 11, 897-903, 2003.

[26] Van Hemel C., Barriers and stimuli for ecodesign in SMEs, Journal of Cleaner Production, 10, 439-453, 2002.

[27] www.labs.autodesk.com/technologies/sustainable_ materials_assistant

[28] Information materials on SolidWorks Sustainability, Dassault Systèmes, 2013.

[29] Wooldridge M., An Introduction to multiagent system, John Wiley \& Sons, 2002. 